\title{
BMJ Open Exploratory application of the Ages and Stages (ASQ) child development screening test in a low-income Peruvian shantytown population
}

\author{
Victoria Kyerematen, ${ }^{1}$ Averine Hamb, ${ }^{2}$ Richard A Oberhelman, ${ }^{3}$ Lilia Cabrera, ${ }^{4}$ \\ Antonio Bernabe-Ortiz, ${ }^{5}$ Susan J Berry ${ }^{6}$
}

To cite: Kyerematen $\mathrm{V}$, Hamb A, Oberhelman RA, et al. Exploratory application of the Ages and Stages (ASQ) child development screening test in a lowincome Peruvian shantytown population. BMJ Open 2014:4:e004132. doi:10.1136/bmjopen-2013004132

- Prepublication history for this paper is available online. To view these files please visit the journal online (http://dx.doi.org/10.1136/ bmjopen-2013-004132).

Received 27 September 2013 Revised 11 December 2013 Accepted 12 December 2013

CrossMark

For numbered affiliations see end of article.

Correspondence to Dr Richard A Oberhelman; oberhel@tulane.edu

\section{ABSTRACT}

Objectives: Public health research on child health is increasingly focusing on the long-term impacts of infectious diseases, malnutrition and social deprivation on child development. The objectives of this exploratory study were to (1) implement the Ages and Stages Questionnaires (ASQ) in children aged 3 months to 5 years in a low-income Peruvian population and (2) to correlate outcomes of the ASQ with risk factors such as nutritional status, diarrhoea incidence and wealth index.

Setting: Primary data collection was carried out in the Pampas de San Juan de Miraflores, a periurban lowincome community in Lima, Peru.

Participants: The study population included 129 children selected through community census data, with a mean age of 22 months (SD 6.8) and with almost equal gender distribution ( $51 \%$ males).

Intervention: A Peruvian psychologist administered the age-appropriate (ASQ2 for participants enrolled in 2009, ASQ3 for participants enrolled in 2010). Results of the ASQ are reported separately for five scales, including Communication, Gross Motor, Fine Motor, Problem Solving and Personal-Social.

Primary and secondary outcome measures:

For each scale, results are reported as normal or suspect, meaning that some milestone attainment was not evident and further evaluation is recommended.

Results: Overall, 50 of 129 children (38.7\%) had suspect results for at least one of the five scales, with the highest rates of suspect results on the Communication (15.5\%) and Problem Solving scales $(13.9 \%)$. Higher rates of suspect outcomes were seen in older children, both overall $(p=0.06)$ and on Problem Solving ( $p=0.009)$, and for some scales there were trends between suspect outcomes and wealth index or undernutrition.

Conclusions: The ASQ was successfully applied in a community-based study in a low-income Peruvian population, and with further validation, the ASQ may be an effective tool for identifying at-risk children in resource-poor areas of Latin America.

\section{Strengths and limitations of this study}

- We demonstrated the feasibility of conducting developmental screening with a simple questionnaire-based test in a low-income periurban paediatric population in Peru, using a standardised and systematic study design.

- The availability of demographic data and clinical data on nutrition and diarrhoeal diseases allowed us to evaluate correlations between potential risk factors and adverse outcomes in five different developmental screening scales.

- As a pilot study with limited funding, the project sample size was limited.

- Limited resources also did not allow us to validate the Ages and Stages Questionnaires against a standardised developmental assessment tool.

\section{INTRODUCTION}

Public health research on child health is increasingly focusing on the long-term impact of infectious diseases, malnutrition and social deprivation on psychosocial outcomes such as child development. Studies carried out in the 1990s to assess the effect of anthelmintic drugs on growth, development and academic performance of children with intestinal helminths ${ }^{1}{ }^{2}$ have spurred interest in looking at potential relationships between developmental outcomes and other common diseases of children from resourcepoor areas, such as diarrhoea, respiratory infections and malaria. ${ }^{3}$

Developmental screening tests have been used for decades to help identify children with developmental or behavioural disabilities. Prior to the development of screening tests, detection of developmental delays was based on unstandardised physician knowledge and individual informal screening tests. This non-standardised approach in detecting developmental delays results is generally 
unreliable, and early research suggests that physicians who use clinical judgement alone detect less than $30 \%$ of children with developmental impairments. ${ }^{4}$

One of the challenges of research studies exploring developmental outcomes is the need for simple tools that can adequately screen a child's developmental status and identify at-risk children in a clinic or community setting. This initial screening process allows clinicians to find at-risk children who can then receive a more complete developmental assessment using tools such as the Bayley Scales of Infant and Toddler Development. The first widely used developmental screening test used for this purpose, the Denver Developmental Screening Test, was created in the 1960s through the synthesis of 12 developmental and preschool intelligence tests to standardise the screening process. ${ }^{5}$ While the Denver test was generally effective in the USA, there were several different instances where the tool proved to be problematic in the screening of different ethnic groups. ${ }^{6-8}$

In recent years, traditional developmental screening tests such as the Denver Developmental Screening Test II are being replaced in many practice settings by simple, questionnaire-based tests. One of these tests, the Ages and Stages Questionnaires (ASQ2 and ASQ3) was developed as an alternative-screening tool in the 1980s and revised in 2009, culminating in the ASQ3. ${ }^{9}$ Recent literature suggests that the ASQ is an appropriate screening tool for different cultures and has been used widely in a variety of countries including Brazil, Norway, Korea, Taiwan, India and Ecuador. ${ }^{8} 10$ The ASQ is available in Spanish and English, which makes application possible in diverse Spanish-speaking populations in Latin America. In a study in the Cayambe-Tabacundo region in Ecuador, investigators found an association between stunting or low birthweight and low maternal education with deficits in gross motor and communication skills using the ASQ. ${ }^{11}$ Another study in Brazil similarly found that cognitive performance later in childhood is correlated with incidence of diarrhoea before the age of 2 years. ${ }^{3}$ A 14-year cohort study based in a Brazilian shantytown found that there was impairment in semantic but not phonetic fluency among children who had frequent diarrhoea, ${ }^{12}$ suggesting that early childhood diarrhoea may have an influence on language development.

\section{MATERIALS AND METHODS}

In this preliminary study we applied the ASQ2 and ASQ3 and explored potential correlations between typical child developmental milestones and either diarrhoea incidence or undernutrition in a high-risk Peruvian population. The study participants were children aged 3 months to 5 years enrolled in a locally funded ongoing parasitic and viral diarrhoea surveillance project in the Pampas de San Juan de Miraflores in Lima, Peru. Wealth index information is based on the classification by Pantazis et $a l^{13}$ classifying children into groups of more deprivation and lesser deprivation based on access to basic necessities, rather than on monetary income. Diarrhoea incidence rates are based on parental reports from data recorded during the previous year. Classification of undernutrition is based on CDC reference standards, using less than $90 \%$ of the mean weight-for-age as the cut-off value for undernutrition based on Gomez criteria widely used in Latin America. ${ }^{14}$

Potential participants were identified from a convenience sample that included children in the target age group identified through the diarrhoea study database. Following verbal parental informed consent, a Peruvian psychologist administered the age-appropriate ASQ (ASQ2 for participants enrolled in 2009, ASQ3 for participants enrolled in 2010) in the home setting, and staff conducting the test solicited parent input when needed to supplement behavioural observations. The questionnaire takes about $30 \mathrm{~min}$ to administer. Results of the ASQ are reported separately for five scales, including Communication, Gross Motor, Fine Motor, Problem Solving and Personal-Social. For each scale, results are reported as normal or suspect. 'Suspect' results indicate that the child's score was below the cut-off score established for the ASQ3 in the US population, some milestone attainment was not evident, and further evaluation is recommended. The mother received an explanation of the results in addition to a list of suggestions for further testing, if necessary. Data were entered into a database using Microsoft Excel and analysed using STATA V.11.0 with dichotomous variables analysed by Fisher's exact test and continuous variables by Mann-Whitney U test, where appropriate.

\section{RESULTS}

The average age of the 129 children enrolled was 22 months (SD 6.8) and there were slightly more males than females enrolled (table 1). Seventy-seven children (59.7\%) were assessed with the ASQ2, and the remainder with the ASQ3. According to the wealth index, the population was fairly equally divided between the two groups (ie, lower and higher wealth attainment). Almost one-quarter of the children had mild malnutrition based on weight-for-age, using Center for Disease Control growth standards.

Overall, 50 children $(38.7 \%)$ had suspect results for at least one of the five scales. Suspect results were found in 20 children for the Communication scale (15.5\%), 5 for Gross Motor (3.8\%), 13 for Fine Motor (10\%), 18 for Problem Solving (13.9\%) and 7 for the Personal-Social scale $(5.4 \%)$. Thirteen children had delays in more than one scale. When the 50 children with at least one suspect result were compared with the 79 children with no suspect results, no significant differences were seen based on mean age, sex, test used, wealth index, diarrhoea rate or rate of undernutrition. However, when age was examined as a stratified variable $(<20$ vs $\geq 20$ 


\begin{tabular}{|c|c|}
\hline Characteristic & $\mathbf{N}(\%)$ \\
\hline Age, in months (mean $\pm S D$ ) & $22.6 \pm 6.8$ \\
\hline \multicolumn{2}{|l|}{ Age (months) } \\
\hline$<20$ & $50(38.8)$ \\
\hline$\geq 20$ & 79 (61.2) \\
\hline \multicolumn{2}{|l|}{ Sex } \\
\hline Male & $66(51.2)$ \\
\hline Female & $63(48.8)$ \\
\hline \multicolumn{2}{|l|}{ Questionnaire used } \\
\hline ASQ2 & $77(59.7)$ \\
\hline ASQ3 & $52(40.3)$ \\
\hline \multicolumn{2}{|l|}{ ASQ results } \\
\hline Normal & $79(61.2)$ \\
\hline Suspect & $50(38.8)$ \\
\hline \multicolumn{2}{|l|}{ Wealth index } \\
\hline Lowest (poorer) & $71(55.0)$ \\
\hline Highest (richer) & $58(45.0)$ \\
\hline \multicolumn{2}{|l|}{ Diarrhoea rate (year) } \\
\hline Mean $\pm S D$ & $9.2(6.3)$ \\
\hline \multicolumn{2}{|l|}{ Undernutrition } \\
\hline No (normal) & $99(76.7)$ \\
\hline Yes (grade 1) & $30(23.3)$ \\
\hline
\end{tabular}

months), a trend towards higher rates of suspect outcomes in the older children was seen $(\mathrm{p}=0.06$; table 2$)$.

We also compared children with suspect results versus normal results for each of the five scales. In most cases no significant differences were observed between groups, and few variables with significant differences or trends towards significant differences are presented in table 2. For the Problem Solving scale, children with suspect results were significantly older (mean 28.1 vs 21.7 months, $\mathrm{p}=0.001$ ) than children with normal results. Trends towards significant differences were observed on the Communication scale based on wealth index, and also on the Gross Motor scale based on the presence of undernutrition.

\section{DISCUSSION}

Our findings indicate a trend towards association between age and at least one suspect outcome on any of the five scales in this low-income Peruvian population. This is likely related to the strong association between older age group ( $\geq 20$ months) and suspect outcome on the Problem Solving scale. A commonly missed question in the range 24-33 months tests the child's ability to integrate by asking the child to identify an unfinished snowman. Children in the Pampas de San Juan community are usually unfamiliar with a snowman, so it may be unrealistic to expect a child to recognise an unfinished snowman. That particular question had one of the highest frequencies of incorrect answers as defined by the ASQ3, suggesting the need for other potentially culturally biased questions to be re-evaluated for relevance in different settings. While the 'snowman question' may have contributed to the high rate of suspect results on the problem solving scale, this question was not the sole reason for the results observed since children would have to miss several other items in that domain to fall into the 'suspect' category.

The association between wealth index and suspect outcome on the communication scale was very close to

Table 2 Outcomes with trends towards significant differences

\begin{tabular}{|c|c|c|c|}
\hline Characteristic & Suspect & Normal & p Value \\
\hline$\geq 20$ & $36(72.0 \%)$ & $43(54.4 \%)$ & \\
\hline Communication & $N=20$ & $N=109$ & \\
\hline \multicolumn{4}{|l|}{ Sex } \\
\hline \multicolumn{4}{|l|}{ Wealth index $†$} \\
\hline Lowest (poorer) & $15(75.0 \%)$ & $56(51.4 \%)$ & 0.06 (NS) \\
\hline Highest (richer) & $5(25.0 \%)$ & $53(48.6 \%)$ & \\
\hline Gross Motor & $\mathrm{N}=5$ & $\mathrm{~N}=124$ & \\
\hline \multicolumn{4}{|l|}{ Undernutrition (Gomez)† } \\
\hline$<20$ & $2(11.1 \%)$ & 48 (43.2\%) & 0.009 \\
\hline$\geq 20$ & $16(88.9 \%)$ & $63(56.8 \%)$ & \\
\hline
\end{tabular}


significant ( $\mathrm{p}$ value $=0.06$ ) and a larger sample size would likely result in statistical significance. Interestingly, the two scales with the highest rates of at-risk finding in our study were the same ones that were most commonly flagged as 'delayed' in the Ecuador study (Communication and Problem Solving), especially in the older ( $\geq 20$ months) children. There was also a trend towards significance $(p=0.08)$ on the gross motor scale based on malnutrition. This is consistent with the current literature that suggests malnutrition is associated with delayed growth, which may in turn be associated with delays in gross motor skills.

This exploratory study has several limitations. Our limited sample size may not have allowed detection of differences that would have been evident with a larger population, as suggested by many associations that were not significant at the $\mathrm{p}<0.05$ level but with $\mathrm{p}$ values less than 0.10 . Although the current literature suggests that the ASQ may have cross-cultural validity, the ASQ test has not been validated in this Peruvian population, and the total sample size was limited by logistics and fundings. Differences between the ASQ2 and the ASQ3 may have influenced study results, although the ASQ authors found few significant differences between the ASQ2 and ASQ3, which supports the logic of combining the two samples. This convenience sample did not allow for validation and reliability studies that would be needed to adapt the current test to our population. Despite these limitations, we were able to apply this developmental screening tool in a community-based study in a lowincome Peruvian population, and with further validation to study cut-off scores and any necessary adaptations with a larger, normative sample the ASQ may be an effective tool for identifying at-risk children in resourcepoor areas of Latin America.

\section{Author affiliations \\ ${ }^{1}$ Duke Global Health Institute, Durham, North Carolina, USA \\ ${ }^{2}$ College of Health Professions, Mercer University, Atlanta, Georgia, USA \\ ${ }^{3}$ Department of Global Community Health and Behavioral Sciences, Tulane School of Public Health and Tropical Medicine, New Orleans, Louisiana, USA ${ }^{4}$ Asociación Benéfica Proyectos en Informatica, Salud, Medicina, y Agricultura (PRISMA), Lima, Peru \\ ${ }^{5}$ School of Public Health and Administration; CRONICAS Center of Excellence in Chronic Diseases, Universidad Peruana Cayetano Heredia, Lima, Peru ${ }^{6}$ Department of Pediatrics, Louisiana State University School Health Science Center, New Orleans, Louisiana, USA}

Acknowledgements The authors would like to thank the residents of the Pampas de San Juan de Miraflores in Lima, Peru for their participation in this study, as well as the staff of the Asociación Benéfica PRISMA in this community for their diligent work and valuable assistance.

Contributors All authors contributed to the study design, discussions of results and preparation of the final article. VK and $\mathrm{AH}$ were involved in participant enrolment, data collection and data presentation. RAO directed the study design, oversight of other investigators, data analysis and presentation, and preparation of manuscripts. LC had primary responsibility for supervision of field staff and logistics in the study community. AB-0 led the data analysis and statistical interpretation. SJB contributed to the selection of developmental screening tests and interpretation of testing results. All authors approved the final submitted version of the paper.

Funding This study was funded by the Tulane-Xavier Minority Health International Research Training (MHIRT) Programme, supported by a training grant from the U.S. National Institutes of Health (T37 MD001424).

\section{Competing interests None.}

Ethics approval The study was approved by Institutional Review Boards from Tulane University, Xavier University of Louisiana, and the Asociacion Benefica PRISMA in Lima, Peru.

Provenance and peer review Not commissioned; externally peer reviewed.

Data sharing statement No additional data are available.

Open Access This is an Open Access article distributed in accordance with the Creative Commons Attribution Non Commercial (CC BY-NC 3.0) license, which permits others to distribute, remix, adapt, build upon this work noncommercially, and license their derivative works on different terms, provided the original work is properly cited and the use is non-commercial. See: http:// creativecommons.org/licenses/by-nc/3.0/

\section{REFERENCES}

1. Adams EJ, Stephenson LS, Latham MC, et al. Physical activity and growth of Kenyan school children with hookworm, Trichuris trichiura and Ascaris lumbricoides infections are improved after treatment with albendazole. J Nutr 1994;124:1199-206.

2. Stephenson LS, Latham MC, Adams EJ, et al. Physical fitness, growth and appetite of Kenyan school boys with hookworm, Trichuris trichiura and Ascaris lumbricoides infections are improved four months after a single dose of albendazole. $J$ Nutr 1993;123:1036-46.

3. Guerrant DI, Moore SR, Lima AA, et al. Association of early childhood diarrhea and cryptosporidiosis with impaired physical fitness and cognitive function four-seven years later in a poor urban community in northeast Brazil. Am J Trop Med Hyg 1999;61:707-13.

4. Glascoe FP. Re: parents' evaluation of developmental status. J Paediatr Child Health 2005;41:615-16; author reply 616.

5. Frankenburg WK, Dodds JB. The Denver Developmental Screening Test. J Pediatr 1967;71:181-91.

6. Fung KP, Lau SP. Denver Developmental Screening Test: cultural variables. J Pediatr 1985;106:343.

7. Tsai H-LA, McClelland MM, Pratt C, et al. Adaption of the 36-month Ages and Stages Questionnaire in Taiwan: results from a preliminary study. J Early Interv 2006;28:213-25.

8. Kerstjens JM, Bos AF, ten Vergert EM, et al. Support for the Global Feasibility of the Ages and Stages Questionnaire as developmental screener. Early Hum Dev 2009;85:443-7.

9. Hix-Small H, Marks K, Squires J, et al. Impact of implementing developmental screening at 12 and 24 months in a pediatric practice. Pediatrics 2007:120:381-9.

10. Filgueiras A, Pires P, Maissonette S, et al. Psychometric properties of the Brazilian-adapted version of the Ages and Stages Questionnaire in public child daycare centers. Early Hum Dev 2013;89:561-76.

11. Handal AJ, Lozoff B, Breilh J, et al. Sociodemographic and nutritional correlates of neurobehavioral development: a study of young children in rural region of Ecuador. Rev Panam Salud Publica 2007;21:292-300.

12. Patrick PD, Oriá RB, Madhavan V, et al. Limitations in verbal fluency following heavy burdens of early childhood diarrhea in Brazilian shantytown children. Child Neuropsychol 2005;11:233-44.

13. Pantazis C, Gordon D, Levitas R. eds. Poverty and social rxclusion in Britain: The Millennium Survey. The Policy Press, 2006.

14. Gomez F, Galvan RR, Frenk S, et al. Mortality in second and third degree malnutrition. J Trop Pediatr 1956;2:77-83. 